\title{
Epoxy composites filled with boron nitride: cure kinetics and the effect of particle shape on the thermal conductivity
}

\author{
Sasan Moradi $^{1}$ (D) Yolanda Calventus $^{1}$ (D) $\cdot$ Frida Román $^{1}$ (D) $\cdot$ Pol Ruiz ${ }^{1} \cdot$ John M. Hutchinson $^{1}$ (D)
}

Received: 22 July 2019 / Accepted: 23 April 2020

(c) Akadémiai Kiadó, Budapest, Hungary 2020

\begin{abstract}
Thermally conducting and electrically insulating materials have been prepared by filling an epoxy-thiol system with boron nitride (BN) particles of different shapes (platelets and agglomerates) and sizes (from 2 to $180 \mu \mathrm{m}$ ), and hence with different specific surface areas. The cure kinetics has been studied by differential scanning calorimetry in both non-isothermal and isothermal modes, and it has been shown that there is a systematic dependence of the cure kinetics on the BN content, the cure reaction generally being retarded by the addition of the BN particles. For filler loadings greater than about 30 vol\%, the retardation of the cure, in both isothermal and non-isothermal mode, appears also to decrease as the specific surface area decreases. For the smallest $(2 \mu \mathrm{m})$ platelets, which have a significantly higher specific surface area $\left(10 \mathrm{~m}^{2} \mathrm{~g}^{-1}\right)$, the retardation is particularly pronounced, and this aspect is rationalized in terms of the activation energy and frequency factor of the reaction. The thermal conductivity of the cured epoxy-thiol-BN composites has been measured using the transient hot bridge method and is found to increase in the usual way with increasing BN content for all the particle types and sizes. For the platelets, the thermal conductivity increases with increasing particle size, mirroring the effect of BN content on the cure kinetics. The agglomerates, though, give the highest values of thermal conductivity, contrary to what might be expected in the light of their specific surface areas. Scanning electron microscopy of the fracture surfaces of the cured composites has been used to show that the interface between epoxy matrix and filler particles is better for the agglomerates. This, together with the reduced interfacial area, explains their higher thermal conductivity.
\end{abstract}

Keywords Boron nitride $\cdot$ Epoxy composites $\cdot$ Thermal conductivity $\cdot$ DSC $\cdot$ Cure kinetics $\cdot$ Specific surface area

\section{Introduction}

With the rapid development of modern electronics towards miniaturization, multi-functionalization and high-performance, overheating is a serious problem confronted by many electrical devices, because a significant increase in temperature will result in a deterioration in the performance of the device, and a reduction in its lifetime and reliability [1]. The efficient removal of the accumulated heat from these devices has become one of the key issues in the thermal management field [2]. Polymers have been used widely as the material for electronic packaging, due to their several merits, such as electrical insulation, lightweight, low cost and ease of

John M. Hutchinson

hutchinson@mmt.upc.edu

1 Departament de Màquines i Motors Tèrmics, ESEIAAT , Universitat Politècnica de Catalunya, C/Colom 11, 08222 Terrassa, Spain processing [3]. However, the thermal conductivity of pure polymers is normally lower than $0.5 \mathrm{~W} \mathrm{~m}^{-1} \mathrm{~K}^{-1}$, which greatly limits their range of applications in respect of heat transfer. Enhancing the thermal conductivity of polymers is therefore in great demand.

One possibility is to enhance the intrinsic thermal conductivity of the polymers by the alignment of the polymer chains [4-7], but the high cost and complicated process are two major barriers for the large-scale application of this method. Besides engineering the structure and morphology of the polymer itself, another effective approach to enhance the thermal conductivity of the material is to incorporate into the polymer matrix a proportion of thermally conductive fillers, such as metals [8-10], ceramics [11, 12], carbonbased materials [13] and their hybrids [14, 15].

The selection of these filler materials is more limited if electrical insulation is to be maintained in addition to achieving high thermal conductivity. For such applications, one of the most widely used fillers in epoxy resin systems 
is boron nitride (BN) [e.g. 16-20]. The results presented in the literature, however, show that there is a large variation in the effectiveness of this filler; to illustrate this, a quite extensive compilation of the thermal conductivity of epoxy-BN systems can be found in reference [21]. The causes of this large variation are manifold, including the following, all of which would be expected to have an effect on the thermal conductivity: the use or otherwise of surface treatments of the filler particles or of coupling agents [22]; the fabrication of the epoxy-BN composites under high pressure [e.g. 14, $16,19,20]$; the use of solvents in the preparation procedure [23]; and the use of BN filler particles of various sizes and in different forms, principally either as platelets or as agglomerates.

It is this last aspect that is of particular interest in the present work. The conduction of heat through the composite material depends on the transport of phonons, which encounter an interfacial thermal resistance (ITR) at the interfaces between the epoxy matrix and the BN filler particles. The ITR consists of two parts: thermal contact resistance resulting from poor mechanical or chemical bonding between the matrix and particles, and thermal boundary resistance, or Kapitza resistance, as a consequence of the different physical properties of the constituent materials. For the same loading of a filler of a given geometry, for example spherical agglomerates, the smaller the filler particles the larger is the surface area, and hence one would anticipate greater ITR for the smaller particles and thus a reduced thermal conductivity. Likewise, the shape of the filler particles plays a similar role: for a given loading, platelets offer a larger surface area than do agglomerates, implying a lower thermal conductivity for the platelet particles. In practice, the situation is not quite as simple as this, and the filler particles are typified by their size and by their Brunauer-Emmett-Teller (BET) specific surface area (SSA), which is determined by the adsorption of a gas, typically nitrogen, onto the surface of the particles at cryogenic temperatures.

However, on account of the porosity of the particles, among other things, there is no direct correlation between the size, geometry and SSA of BN filler particles, as can be seen from a consideration of typical manufacturers' literature [24]. It is not clear, therefore, to what extent the SSA is indicative of the suitability of any given type of BN particle for high thermal conductivity applications. Furthermore, reports in the literature of the effect on the thermal conductivity of adding BN particles often do not specify their SSA, though there are some notable exceptions $[14,18,19$, 25-28], and often they do not make specific reference to the shape of the particles. Consequently, in the present work, we investigate the effect of BN particle shape and SSA on the thermal conductivity of epoxy composites.

In addition, although the $\mathrm{BN}$ particles are inert and hence would not a priori be expected to influence the chemical cure reaction, we have observed earlier that, for this epoxy-thiol system, there are some systematic effects of BN content on the reaction kinetics $[21,29,30]$. These effects were correlated to some extent with the thermal conductivity measurements, suggesting that the matrix-filler interface, so crucial to the thermal conductivity and dependent on SSA and filler particle shape and/or size, plays an important role also in the cure kinetics. This would imply that an analysis of the cure kinetics could throw some light on the mechanisms of conductivity enhancement in these epoxy-BN composites. We therefore include in the present work a calorimetric study of the effects of BN particle shape and SSA.

\section{Materials and methods}

\section{Materials}

The matrix material for these epoxy-BN composites was an epoxy-thiol system initiated by an imidazole. The epoxy resin used was diglycidyl ether of bisphenol-A, DGEBA (Araldite GY 240, Huntsman Advanced Materials, $182 \mathrm{~g} \mathrm{eq}^{-1}$, density $1.17 \mathrm{~g} \mathrm{~cm}^{-3}$ ), the thiol was pentaerythritol tetrakis (3-mercaptopropionate) (Sigma-Aldrich, $488.66 \mathrm{~g} \mathrm{~mol}^{-1}$, density $1.28 \mathrm{~g} \mathrm{~cm}^{-3}$ ), and the initiator was encapsulated imidazole LC-80 (Technicure).

A number of different grades of hexagonal $\mathrm{BN}$ filler were used, either platelets or agglomerates of various sizes. All of these BN particles fall within the category of CarboTherm $^{\text {TM }}$ Thermal Management Fillers and were obtained from Saint-Gobain Boron Nitride [24]. The denomination, average particle size and SSA for the selected platelets were as follows: PCTP2, $2 \mu \mathrm{m}, 10 \mathrm{~m}^{2} \mathrm{~g}^{-1}$; PCTP30, $30 \mu \mathrm{m}, 1 \mathrm{~m}^{2}$ $\mathrm{g}^{-1}$; and PCTP30D, $180 \mu \mathrm{m}, 1 \mathrm{~m}^{2} \mathrm{~g}^{-1}$. The last of these platelets, with average size $180 \mu \mathrm{m}$, is engineered for high shear mixing processes, and has a very wide distribution of particle size, with a maximum particle size of $1600 \mu \mathrm{m}$. Two different agglomerates were used, each with an average size of $120 \mu \mathrm{m}$. The first, PCTL7MHF, has an SSA value of $3.0 \mathrm{~m}^{2} \mathrm{~g}^{-1}$, while the second, CTS7M, denoted as a "spherical powder", has a slightly higher SSA value of $3.5 \mathrm{~m}^{2} \mathrm{~g}^{-1}$ and is designed for use with thermosetting polymers and low shear processing in order to give the best thermal performance [24]. An illustration of the different forms of the platelets and agglomerates can be seen in the scanning electron microscopy (SEM) micrographs in Fig. 1 for the $30 \mu \mathrm{m}$ platelets (PCTP30) and the $120 \mu \mathrm{m}$ agglomerates (PCTL7MHF). All these BN particles were in the form of white powders and were used as received, without any surface treatment.

The different epoxy-BN composite materials were prepared as follows. The initiator, the smallest component and 
Fig. 1 SEM micrographs of $30 \mu \mathrm{m}$ platelets (left, scale bar $10 \mu \mathrm{m})$ and $120 \mu \mathrm{m}$ agglomerates (right, scale bar $100 \mu \mathrm{m}$ )

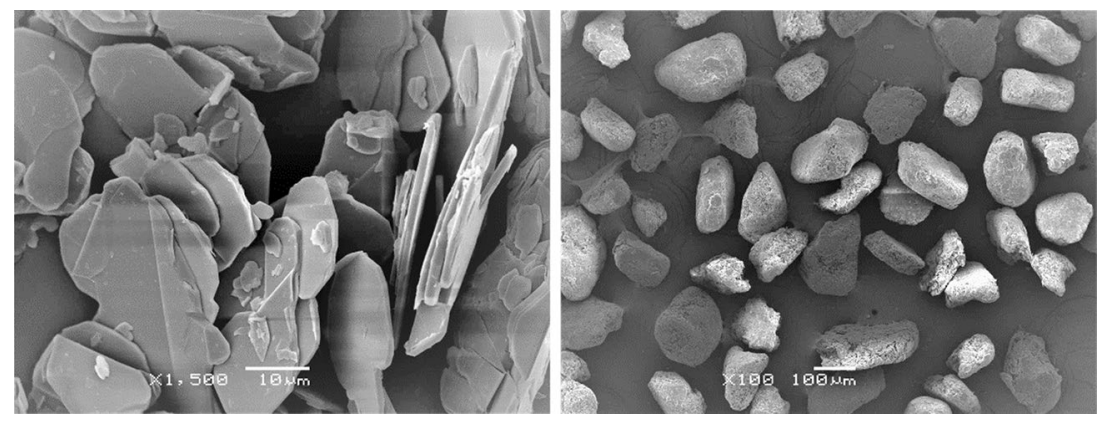

Table 1 Composition by mass of epoxy-thiol samples filled with BN particles with size $x(=2,30$ and 180 for platelets; 120 and 120s for agglomerates) $\mu \mathrm{m}$

\begin{tabular}{lccll}
\hline Sample & Epoxy & BN & Thiol & LC-80 \\
\hline ETL & 100 & 0 & 67 & 2.0 \\
ETLBN $x-10$ & 90 & 10 & 60.3 & 1.8 \\
ETLBN $x-30$ & 70 & 30 & 47 & 1.4 \\
ETLBN $x-50$ & 50 & 50 & 33.5 & 1.0 \\
ETLBN $x-60$ & 40 & 60 & 27 & 0.8 \\
ETLBN $x-70$ & 30 & 70 & 20 & 0.6 \\
\hline
\end{tabular}

in a proportion of 2.0 parts per hundred resin (phr), was first mixed with the thiol, in an amount calculated to maintain a stoichiometric ratio with the epoxy resin (approximately 60:40 epoxy/thiol by mass), and then the epoxy resin was added and mixed thoroughly. To obtain the epoxy-BN composite, an appropriate amount of the selected BN filler was added in a proportion which would give mass percentages of $10,30,50,60$ and occasionally 70 , with respect to the combined mass of the BN and epoxy. The total mass of the mixture was typically up to $10 \mathrm{~g}$ maximum, which can conveniently and efficiently be mixed in a glass beaker with a stirring rod. All the measured components were mixed in this way by hand for about $10 \mathrm{~min}$, until the appearance was homogeneous. This final mixture was degassed under vacuum at room temperature for approximately $15 \mathrm{~min}$. The sample denominations and the proportions of all the components in each sample are given in Table 1; the $120 \mu \mathrm{m}$ spherical agglomerates are labelled 120s to distinguish them from the other $120 \mu \mathrm{m}$ agglomerates.

The maximum filler content used, $70 \%$ by mass of $\mathrm{BN}$ with respect to the combined mass of $\mathrm{BN}$ and epoxy, is a consequence of the fact that the mixture becomes an increasingly stiff paste as the BN content increases. This is particularly so for the $2 \mu \mathrm{m}$ platelets, which have a much higher specific surface area in comparison with the other platelets and, to a slightly lesser extent, in comparison with the agglomerates. In fact, it was not possible to fabricate
$70 \%$ composites using the $2 \mu \mathrm{m}$ platelets, as the composites remained with a powdery texture without mechanical integrity. This increased viscosity of the epoxy-BN mixture for the highest $\mathrm{BN}$ contents has some important consequences; in particular, the degassing procedure becomes ineffective and it is likely that the air bubbles entrained during the mixing will remain in the sample, with a detrimental effect on the thermal conductivity.

It should be pointed out that, for the application of these epoxy-BN composites as the dielectric layer in insulated metal substrates [31], both the very high viscosity of the $70 \%$ composites and the large size of the $180 \mu \mathrm{m}$ platelets make these materials unrealistic from a practical point of view. Nevertheless, their inclusion in this work is justified on the basis that we are studying the effects of BN particle content, size and type on the cure kinetics and thermal conductivity of these composite materials.

\section{Methods}

\section{Differential scanning calorimetry}

The cure reaction kinetics of the epoxy-BN composites was monitored, in both isothermal and non-isothermal (constant heating rate) modes, by differential scanning calorimetry (DSC). In each case, a small sample mass of about $10 \mathrm{mg}$ of the uncured mixture was carefully placed in an aluminium capsule, crimped with a lid with a pierced hole for the release of gas. The DSC experiments were performed using a conventional DSC (DSC821e, Mettler Toledo). The aluminium capsules containing the samples were placed on a rotary sample holder from which a robot arm selected the required sample as programmed and placed it in the DSC furnace. A continuous flow of dry nitrogen gas at $50 \mathrm{~mL} \mathrm{~min}{ }^{-1}$ was maintained throughout all experiments, and controlled cooling rates and sub-ambient temperatures were achieved by means of an intra-cooler. The data evaluation was performed with the STAR ${ }^{\mathrm{e}}$ software, and the DSC was calibrated for both heat flow and temperature using indium with a purity $>99.999 \%$. 
For the isothermal cure measurements, the robot selected the encapsulated composite sample and placed it in the DSC furnace, which had previously been controlled at the required isothermal cure temperature, and the experiment was started immediately. The DSC measured the heat flow as a function of time for the duration of the programmed isothermal experiment, which varied depending on the cure temperature. For these epoxy-BN composites, for which the glass transition temperature of the fully cured system, $T_{\mathrm{g} \infty}$, is about $53{ }^{\circ} \mathrm{C}$, cure temperatures, $T_{\mathrm{c}}$, of $60{ }^{\circ} \mathrm{C}, 70^{\circ} \mathrm{C}$ and $80{ }^{\circ} \mathrm{C}$ were used. Since $T_{\mathrm{c}}>T_{\mathrm{g} \infty}$, no vitrification should occur during cure. In the isothermal experiment, the exothermic heat flow passes through a maximum at a cure time denoted as $t_{\mathrm{p}}$, which is used to characterize the isothermal cure kinetics, and the exothermic heat of reaction is calculated from the area under the cure curve. In order to check that there was no residual heat of reaction, which would be observed if vitrification had occurred or if insufficient cure time had been programmed, a second scan was made in nonisothermal mode at $10{ }^{\circ} \mathrm{C} \mathrm{min}^{-1}$, from which $T_{\mathrm{g} \infty}$ was also determined.

For the non-isothermal cure experiments, the encapsulated composite sample was introduced by the robot into the DSC furnace, previously controlled at $25^{\circ} \mathrm{C}$. It was then cooled at $20{ }^{\circ} \mathrm{C} \min ^{-1}$ to $-65^{\circ} \mathrm{C}$, before being scanned at the required rate of 2,5 or $10^{\circ} \mathrm{C} \mathrm{min}^{-1}$ to $200{ }^{\circ} \mathrm{C}$. The DSC measures the exothermic heat flow, which passes through a maximum at a temperature, $T_{\mathrm{p}}$. This temperature is used to characterize the non-isothermal cure kinetics, while the exothermic heat of reaction is calculated from the area under the cure curve. Immediately after the non-isothermal cure experiment, the sample is cooled at $20^{\circ} \mathrm{C} \min ^{-1}$ to $25^{\circ} \mathrm{C}$ and then reheated at $10{ }^{\circ} \mathrm{C} \min ^{-1}$ to $120^{\circ} \mathrm{C}$ in order to determine $T_{\mathrm{g} \infty}$.

\section{Thermal conductivity}

Samples in the form of parallelepipeds with dimensions $10 \mathrm{~mm} \times 40 \mathrm{~mm} \times 4 \mathrm{~mm}$ were prepared by casting the epoxy-thiol-BN mixture into silicone moulds, degassing under vacuum and curing isothermally at $70{ }^{\circ} \mathrm{C}$ in an aircirculating oven for $1 \mathrm{~h}$. Three such samples were prepared for each composition, of which two are required for the measurement of thermal conductivity. The $10 \mathrm{~mm} \times 40 \mathrm{~mm}$ surfaces of these samples were carefully polished by hand using emery paper (120, 400 and 600 grit size, in sequence), in order to provide the necessary thermal contact with the sensor.

The measurements of the thermal conductivity were taken using the transient hot bridge method (Linseis, THB-100) and a Kapton Hot Point sensor calibrated with polymethyl methacrylate, borosilicate crown glass, marble, a Ti-Al alloy and titanium, covering a range of thermal conductivities from $0.2 \mathrm{Wm}^{-1} \mathrm{~K}^{-1}$ to above $10 \mathrm{Wm}^{-1} \mathrm{~K}^{-1}$. The sensor is placed between the two polished surfaces of the samples, and pressure is applied manually by means of a press. When a controlled heating power, typically $50 \mathrm{~mW}$, is applied to the sensor, the heat is dissipated into the sample, and the higher the thermal conductivity of the sample the more rapidly is the heat dissipated. TheTHB-100 instrument measures the temperature rise in the sample, $\Delta T$, as a function of the time, $t$, for the duration of the heating, typically $100 \mathrm{~s}$. A plot of $\Delta T$ as a function of $1 / \sqrt{ } t$ presents a linear region, and the extrapolation to $1 / \sqrt{ } t=0$ permits the evaluation of the thermal conductivity, $\lambda$ [32]. For each sample, a series of four measurements was made, with an appropriate time interval between measurements for the sample to return to its initial state. The variation between these measurements was typically $\pm 0.05 \mathrm{~W} \mathrm{~m}^{-1} \mathrm{~K}^{-1}$.

\section{Results and discussion}

\section{Differential scanning calorimetry}

Typical non-isothermal DSC cure curves, at a heating rate of $5{ }^{\circ} \mathrm{C} \mathrm{min}{ }^{-1}$, for the epoxy-thiol system without BN (ETL) and for the filled epoxy-thiol-BN composite systems are shown in Fig. 2. The filled systems included here are those with $2 \mu \mathrm{m}$ and $30 \mu \mathrm{m}$ platelets, and those with the $120 \mu \mathrm{m}$ spherical agglomerates. The $\mathrm{BN}$ contents range from 3.7 to $44.7 \mathrm{vol} \%$, except for the $120 \mu \mathrm{m}$ particles for which it was not possible to obtain a homogeneous mixture with 44.7 vol\% of BN. Similar results were obtained also for heating rates of 2 and $10{ }^{\circ} \mathrm{C} \mathrm{min}{ }^{-1}$.

The decrease in the peak height and area as the BN content increases is a consequence of the decreasing proportion of epoxy resin, the heat flow being normalized with respect to the total sample mass. The exothermic heat of reaction, $\Delta H$, calculated per epoxy equivalent (ee), shows no significant variation with the $\mathrm{BN}$ content or particle size, the average value being $128 \pm 6.8 \mathrm{~kJ} \mathrm{ee}^{-1}$. Likewise, the glass transition temperature of the fully cured system, $T_{\mathrm{g} \infty}$, obtained from a subsequent second scan at $10{ }^{\circ} \mathrm{C} \mathrm{min}-1$, is essentially independent of $\mathrm{BN}$ content and particle size, with values of $54.0 \pm 0.4,53.7 \pm 1.2,53.2 \pm 1.2$ and $52.2 \pm 1.3{ }^{\circ} \mathrm{C}$ for the 2, 30, 120 and $180 \mu \mathrm{m} \mathrm{BN}$ particles, respectively. There appears to be a small decrease in $T_{\mathrm{g} \infty}$ as the particle size increases, but this is not considered to be important here, and we conclude that the epoxy-thiol network structure formed during cure is not significantly influenced by the presence of the filler.

On the other hand, the cure kinetics clearly is affected by the filler, the peak exotherm temperature being displaced to higher values as the BN content increases. This is illustrated in Fig. 3, where additionally the corresponding results 

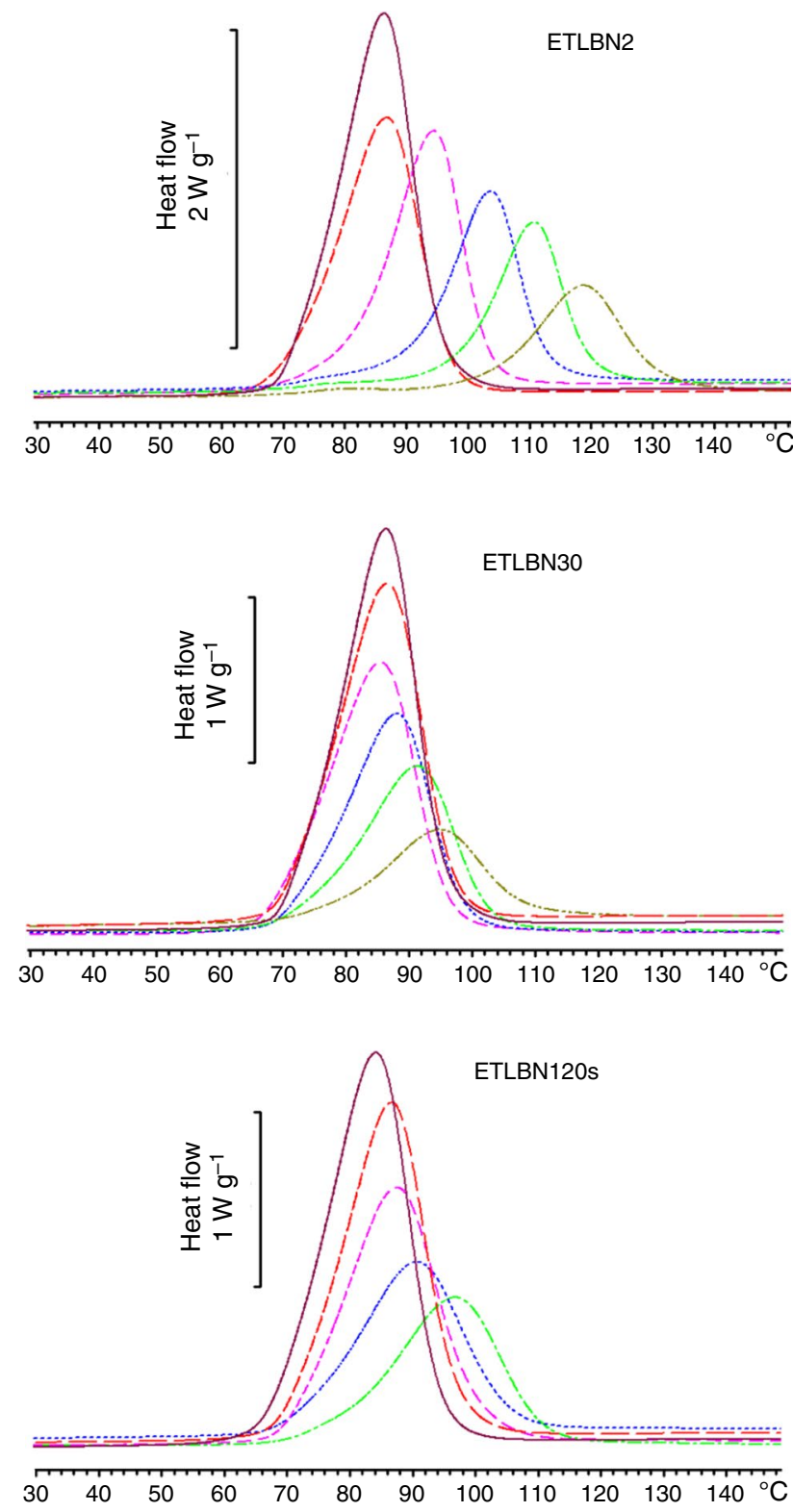

Fig. 2 DSC curves at $5{ }^{\circ} \mathrm{C} \min ^{-1}$ for ETLBN2-y, ETLBN30- $y$ and ETLBN120s- $y$, as indicated, in which $y$ refers to the different $\mathrm{BN}$ contents given in Table 1: purple, full line, $y=0$; long dash, red, $y=10$; short dash, pink, $y=30$; dash-dot, blue, $y=50$; dotted, green, $y=60$; dash-double dot, brown, $y=70$. Note that there is no sample ETLBN120s-70. Exothermic direction upwards

for composites filled with $180 \mu \mathrm{m}$ platelets have also been included. Most noticeably, the shift is much greater for the smallest $(2 \mu \mathrm{m})$ particles, with rather similar shifts for the other particles. This effect, which has been reported in earlier work and occurs also for epoxy-thiol composites filled with aluminium nitride particles, appears to be peculiar to epoxy systems cross-linked with thiol [21, 29, 30].

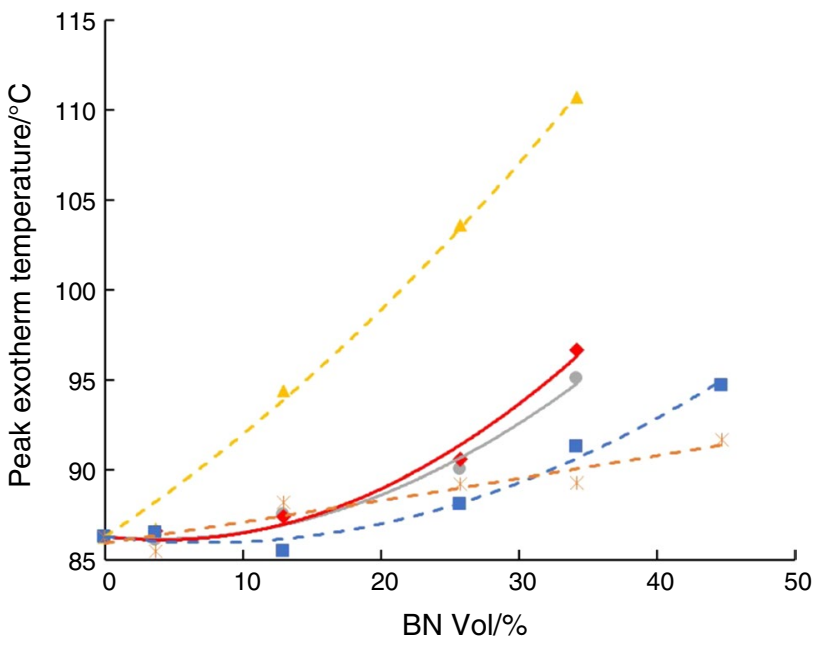

Fig. 3 Peak temperature during non-isothermal cure at $5{ }^{\circ} \mathrm{C} \mathrm{min}^{-1}$ as a function of $\mathrm{BN}$ content for different $\mathrm{BN}$ particles. Platelets, dashed lines: $2 \mu \mathrm{m}$, yellow triangles; $30 \mu \mathrm{m}$, blue squares; $180 \mu \mathrm{m}$, orange asterisks. Agglomerates, full lines: $120 \mu \mathrm{m}$, grey circles; $120 \mu \mathrm{m}$ spherical, red diamonds

Similar results are found for the isothermal cure of these epoxy-thiol-BN systems, for which the isothermal cure curves at $70{ }^{\circ} \mathrm{C}$ are shown in Fig. 4.

Once again, the exothermic heat of reaction, determined from the area under the cure curve and expressed in $\mathrm{kJ} \mathrm{ee}^{-1}$, is found to be essentially independent of the filler content, size and type. The same is true also for the glass transition temperature of the fully cured system, $T_{\mathrm{g} \infty}$, evaluated from a second scan made at $10{ }^{\circ} \mathrm{C} \mathrm{min}{ }^{-1}$. This confirms our earlier conclusion that the epoxy-thiol network structure is not influenced by the presence of the BN filler. On the other hand, the BN content does affect the cure kinetics, in this case quantified by the peak exotherm time, $t_{\mathrm{p}}$. To illustrate this, $t_{\mathrm{p}}$ is plotted in Fig. 5 as a function of the BN content for the different $\mathrm{BN}$ particle sizes and types; again, as for Fig. 3, the results for composites with $180 \mu \mathrm{m}$ platelets have also been included.

From Fig. 3, it appears that the cure reaction is retarded to greater extent not only as the BN content increases but also as the SSA increases $\left(1 \mathrm{~m}^{2} \mathrm{~g}^{-1}\right.$ for the 30 and $180 \mu \mathrm{m}$ platelets, 3.0 and $3.5 \mathrm{~m}^{2} \mathrm{~g}^{-1}$ for the 120 and $120 \mathrm{~s} \mu \mathrm{m}$ agglomerates and $10 \mathrm{~m}^{2} \mathrm{~g}^{-1}$ for the $2 \mu \mathrm{m}$ platelets). This trend, however, is not evident in Fig. 5, though at BN contents greater than $35 \mathrm{vol} \%$ an extrapolation of the agglomerates data may yield this result. It is worth remarking here that the SSA values for the agglomerates are much higher than one might anticipate from their shape, approximately spherical, alone. The reason for this is that the density of the agglomerate particles is significantly less than that of the platelets, implying a degree of porosity in these agglomerates. This implies surface area within the agglomerates for the 

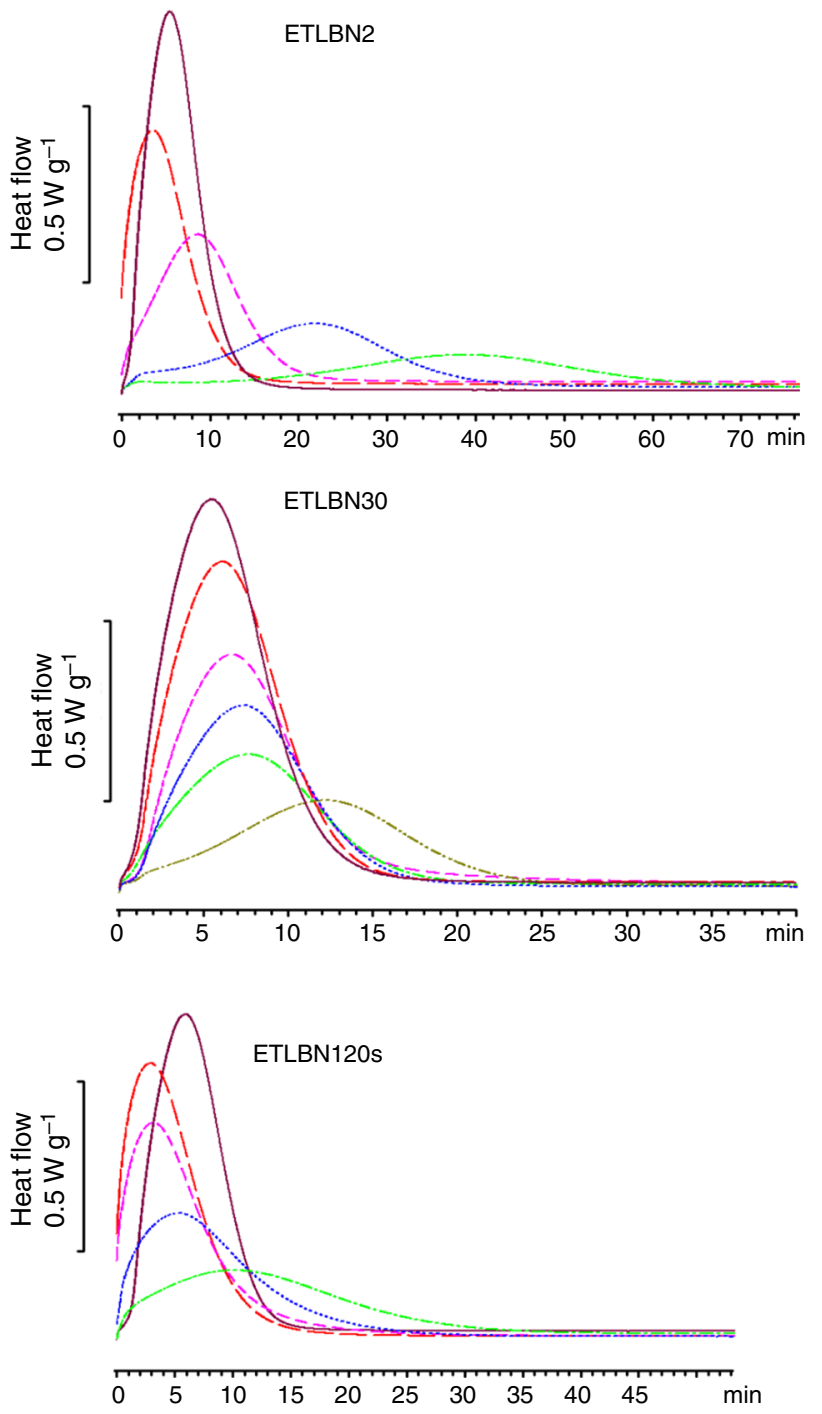

Fig. 4 Isothermal DSC curves at $70{ }^{\circ} \mathrm{C}$ for ETLBN2-y, ETLBN30$y$ and ETLBN120s- $y$, as indicated, in which $y$ refers to the different BN contents given in Table 1: purple, full line, $y=0$; long dash, red, $y=10$; short dash, pink, $y=30$; dash-dot, blue, $y=50$; dotted, green, $y=60$; dash-double dot, brown, $y=70$. Note that there is no sample ETLBN120s-70. Exothermic direction upwards

adsorption of gas in the measurement of the SSA. Support for this interpretation comes from the data provided by the BN manufacturer, Saint-Gobain, where it can be seen [24] that their CarboTherm High Density Agglomerates have a lower SSA $\left(2.5 \mathrm{~m}^{2} \mathrm{~g}^{-1}\right)$ than do the Low Density Agglomerates, such as the PCTL7MHF used here. On the other hand, it is difficult to see why this porosity of the agglomerates should influence the cure kinetics, as the epoxy matrix will only interact with these particles at the outer surface, if indeed there is any interaction. The smooth surfaces of the BN platelets have no available surface functional groups for chemical bonding, but at the edge planes there are hydroxyl and amino groups [33].

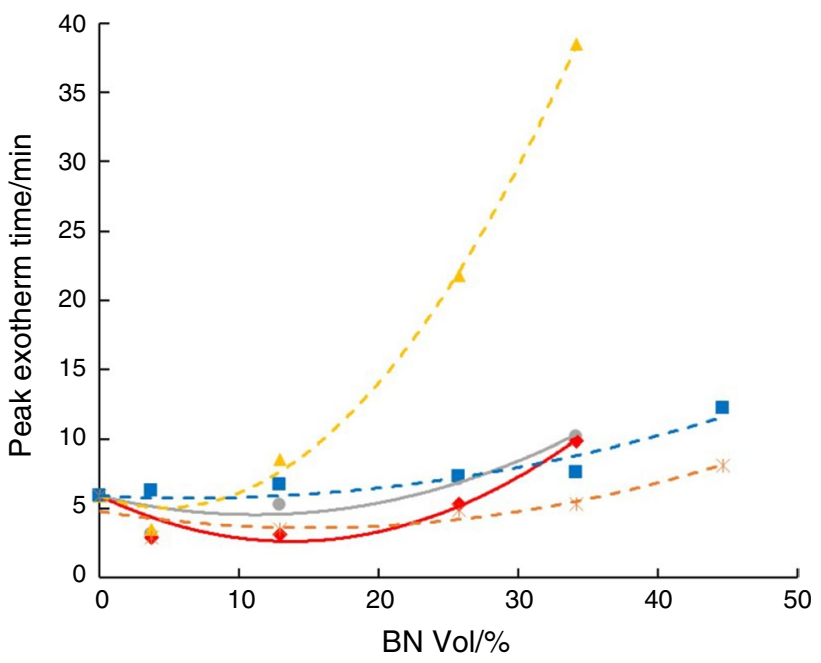

Fig. 5 Peak time during isothermal cure at $70{ }^{\circ} \mathrm{C}$ as a function of $\mathrm{BN}$ content for different BN particles. Platelets, dashed lines: $2 \mu \mathrm{m}$, yellow triangles; $30 \mu \mathrm{m}$, blue squares; $180 \mu \mathrm{m}$, orange asterisks. Agglomerates, full lines: $120 \mu \mathrm{m}$, grey circles; $120 \mu \mathrm{m}$ spherical, red diamonds

Nevertheless, the most striking observation from Figs. 3 and 5 is that the composites with $2 \mu \mathrm{m}$ platelets, for which there is an abundance of edge planes, show a very strong dependence of their cure kinetics on the BN content. It is interesting, therefore, to examine in more detail the cure kinetics of this system. The rate of reaction is a function of temperature, $T$, and of the degree of cure, $\alpha$, according to the equation:

$\frac{\mathrm{d} \alpha}{\mathrm{d} t}=k(T) f(\alpha)$.

The rate constant $k(T)$ follows an Arrhenius temperature dependence with an activation energy, $E_{\mathrm{a}}$ :

$k=A \exp \left(-\frac{E_{\mathrm{a}}}{R T}\right)$

where $A$ is the pre-exponential factor, or frequency factor, with units $\mathrm{s}^{-1}$. In Eq. (1), $f(\alpha)$ is the mathematical expression of the kinetic model, here assumed to be an autocatalytic reaction described by the Sestak-Berggren equation $[34,35]$ :

$f(\alpha)=\alpha^{\mathrm{m}}(1-\alpha)^{\mathrm{n}}$

where $m$ and $n$ are the kinetic exponents of the reaction.

From the non-isothermal cure curves at 2, 5 and $10{ }^{\circ} \mathrm{C} \mathrm{min}^{-1}$, the Kissinger equation $[34,36]$ can be used to determine the activation energy, and the results for ETL and for the ETLBN2- $x$ system up to $x=70$ are given in Table 2. Alternatively, the iso-conversional method [34] can be used to find $E_{\mathrm{a}}$ as a function of the degree of 
Table 2 Activation energy, $E_{\mathrm{a}}$, obtained by the Kissinger equation and by the iso-conversional method for ETL and ETLBN2-30

\begin{tabular}{lll}
\hline Sample & \multicolumn{2}{l}{$E_{\mathrm{a}} / \mathrm{kJ} \mathrm{mol}^{-1}$} \\
\cline { 2 - 3 } & Kissinger & Iso-conversional \\
\hline ETL & 75.3 & 77.1 \\
ETLBN2-10 & 65.3 & - \\
ETLBN2-30 & 66.8 & 54.7 \\
ETLBN2-50 & 68.0 & - \\
ETLBN2-60 & 72.0 & - \\
\hline
\end{tabular}

conversion. For ETL, $E_{\mathrm{a}}$ initially decreases as $\alpha$ increases, then remains rather constant for $\alpha$ between 0.2 and 0.6, before increasing again as the reaction goes to completion. For ETLBN2-30, the only BN content for which this analysis has been made thus far, $E_{\mathrm{a}}$ remains rather constant over the whole range of $\alpha$. The results for these two samples using the iso-conversional analysis and for a degree of cure of 0.5 are included in Table 2 .

The interesting result to note is that the Kissinger analysis indicates that the addition of $\mathrm{BN}$ particles reduces the activation energy, although it increases again for the highest BN content. Likewise, the iso-conversional analysis also shows that $E_{\mathrm{a}}$ decreases on the addition of $\mathrm{BN}$. This result is surprising, as the reaction rate is clearly retarded by the addition of $\mathrm{BN}$, whereas a reduction in $E_{\mathrm{a}}$ would be expected to imply an increase in the rate constant $k$. The conclusion must be that the pre-exponential factor $A$ decreases, and dramatically so when $2 \mu \mathrm{m}$ BN platelets are added. This is an unusual observation; there are rather few reports on the cure kinetics of particulate filled epoxy systems, but two recent studies on epoxy systems filled with BN [37] and alumina [38] find that $A$ remains essentially constant, while the peak exotherm temperature either is unchanged [37] or decreases [38] with increasing filler content. The dramatic decrease in $A$ for the $\mathrm{E}$

TLBN2 system, by more than two orders of magnitude, from $10^{8.6} \mathrm{~s}^{-1}$ for ETL to $10^{6.4} \mathrm{~s}^{-1}$ for ETLBN2-30, as determined by fitting the cure curves with Eqs. (1) to (3), can be explained on the basis of the entropy change, $\Delta S$, of the cure reaction. According to Barghamadi [39], the pre-exponential factor can be written as:

$A=\frac{k_{\mathrm{B}} T}{h} \exp \left(\frac{\Delta S}{R}\right)$

where $k_{\mathrm{B}}$ is Boltzmann's constant, $h$ is Planck's constant, and $R$ is the universal gas constant. Using the above values of $A$ gives entropy changes of $-82 \mathrm{~J} \mathrm{~mol}^{-1} \mathrm{~K}^{-1}$ for ETL and $-124 \mathrm{~J} \mathrm{~mol}^{-1} \mathrm{~K}^{-1}$ for ETLBN2-30. The greater reduction in entropy for the filled system implies that the cured $2 \mu \mathrm{m}$ composite must have fewer configurational states, which
Table 3 Values of $\Delta c_{\mathrm{p}}$ for ETL and for the ETLBN2-y, ETLBN30-y and ETLBN180- $y$ systems for $y=10,30,50$ and 60

\begin{tabular}{lllll}
\hline BN content $y$ & \multicolumn{4}{l}{$\Delta c_{\mathrm{p}} / \mathrm{J} \mathrm{g}^{-1} \mathrm{~K}^{-1}$} \\
\cline { 2 - 5 } & ETL & ETLBN2-y & ETLBN30-y & ETLBN180-y \\
\hline 0 & 0.393 & - & - & - \\
10 & 0.369 & 0.226 & 0.376 & 0.363 \\
30 & 0.312 & 0.197 & 0.292 & 0.264 \\
50 & 0.246 & 0.170 & 0.214 & 0.215 \\
60 & 0.207 & 0.130 & 0.196 & 0.218 \\
\hline
\end{tabular}

needs to be reconciled with $T_{\mathrm{g} \infty}$ being essentially independent of filler content, size and shape. Furthermore, this reduction in entropy must be associated with the much larger interfacial surface area between matrix and filler for the composites filled with $2 \mu \mathrm{m}$ platelets. A possible explanation could be that a significant proportion of the epoxy resin adheres, to a greater or lesser extent, to the large surface area of these particles, and is effectively immobilized, thus reducing its configurational entropy, while the remaining fraction of epoxy participates in the glass transition. Thus, the value of $T_{\mathrm{g} \infty}$ would remain constant, but the change in specific heat capacity, $\Delta c_{\mathrm{p}}$, in units of $\mathrm{J} \mathrm{g}^{-1} \mathrm{~K}^{-1}$ with respect to the total sample mass, would decrease. This is just what is observed, as shown by the results presented in Table 3 .

The value of $\Delta c_{\mathrm{p}}$ for ETL is $0.393 \mathrm{~J} \mathrm{~g}^{-1} \mathrm{~K}^{-1}$, and the table shows that this decreases in proportion with the mass fraction of epoxy matrix in the composites. For the composites with $30 \mu \mathrm{m}$ and $180 \mu \mathrm{m}$ platelets, the values of $\Delta c_{\mathrm{p}}$ follow approximately these scaled values for ETL. On the other hand, the values of $\Delta c_{\mathrm{p}}$ for the $2 \mu \mathrm{m}$ composites are significantly smaller than the corresponding ETL values. We interpret this to mean that for these $2 \mu \mathrm{m}$ composites there is much less epoxy participating in the glass transition because a large proportion is immobilized by the large surface area of the filler particles.

In summary, the dependence of the cure kinetics on the $\mathrm{BN}$ filler content, in both isothermal and non-isothermal cure, can be related to interfacial surface effects, and there is a reasonable correlation with the SSA. Since, for a given BN content, the surface area of agglomerates is much smaller than that of similarly sized platelets, this implies also a difference in cure kinetics between composites filled with agglomerates and those filled with platelets, which might be expected to correspond to different behaviours in respect of the thermal conductivity.

Before presenting the results for the thermal conductivity, however, it is interesting to note that, at relatively low BN contents and most noticeably for isothermal cure, there is a slight acceleration of the cure manifest as a small reduction in the peak exotherm temperature in non-isothermal cure (Fig. 3) or, more noticeably, the peak time in isothermal 
cure (Fig. 5). This occurs to a certain extent for nearly all the samples, even, albeit to a very small extent, for epoxy-BN nanocomposites [see Ref. 40, Fig. 8c]; as was suggested in earlier work [21, 29], it could be a consequence of increased heat transfer in the samples filled with BN. For isothermal cure, in particular, the sample initially at room temperature is inserted into the DSC furnace at the cure temperature, and hence there is inevitably a certain time delay before the sample reaches the cure temperature. The higher the thermal conductivity of the sample, the more rapidly is the heat conducted into the sample from the furnace, and hence the samples filled with BN, ETLBN $x-y$, which have a higher thermal conductivity than the epoxy-thiol alone, will be slightly accelerated with respect to the ETL sample. This effect in combination with the retardation of the cure kinetics on the addition of $\mathrm{BN}$ particles, discussed further above, will give rise to the minimum seen in Fig. 5. On this basis, it would be expected that the samples filled with $120 \mu \mathrm{m}$ spherical agglomerates, which present the most marked minimum in Fig. 5, would have the highest thermal conductivity. This will be examined when the effect of particle size and shape is considered in the next section.

\section{Thermal conductivity}

The thermal conductivity of the various epoxy-thiol-BN composite systems has been determined by the transient hot bridge method, and the results are presented in Fig. 6. Also included in this figure are the results obtained earlier for $180 \mu \mathrm{m}$ platelets [30]. These results show that, as the BN content increases, the thermal conductivity increases for all

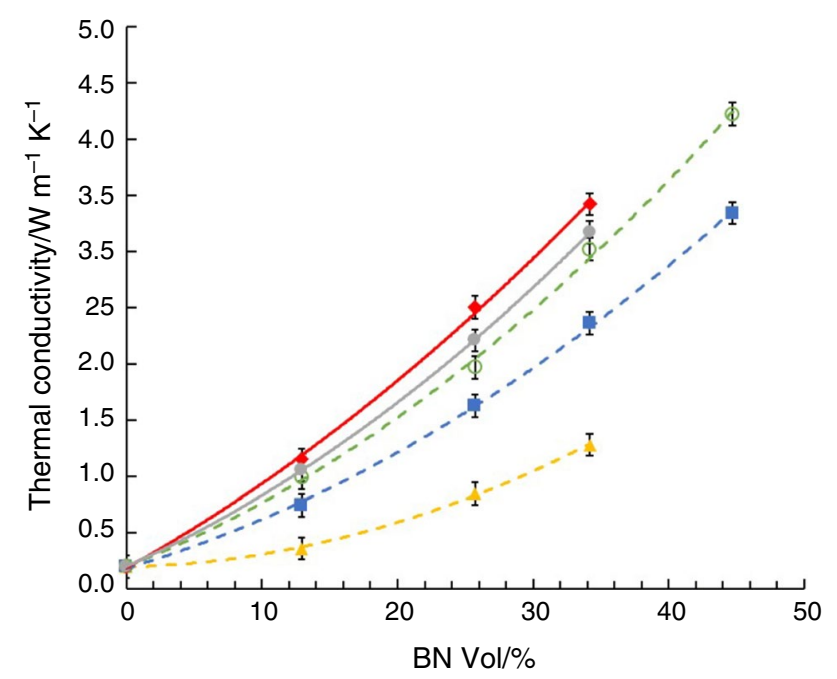

Fig. 6 Thermal conductivity of ETLBN samples as a function of the BN content. Platelets, dashed lines: $2 \mu \mathrm{m}$, yellow triangles; $30 \mu \mathrm{m}$, blue squares; $180 \mu \mathrm{m}$, open green circles. Agglomerates, full lines: $120 \mu \mathrm{m}$, filled grey circles; $120 \mu \mathrm{m}$ spherical, red diamonds. The error bars are $\pm 0.10 \mathrm{~W} \mathrm{~m}^{-1} \mathrm{~K}^{-1}$ the composite systems, and that there is an upward curvature to this dependence, as is commonly observed [21]. For the platelet-shaped BN particles, there is also a systematic increase in the thermal conductivity, for any given BN content, as the platelet size increases. This is consistent with our earlier observations [21] and with other reports in the literature [e.g. 14, 17, 19]. For the larger platelets, it was also possible to achieve filler contents of almost $45 \mathrm{vol} \%$, which was not possible with the $2 \mu \mathrm{m}$ platelets on account of their much higher specific surface area. In this way, the highest thermal conductivity of $4.22 \mathrm{~W} \mathrm{~m}^{-1} \mathrm{~K}^{-1}$ was achieved.

The comparison of the agglomerates with the platelets can now be made. First, both the $120 \mu \mathrm{m}$ and the $120 \mu \mathrm{m}$ spherical filler particles give the highest thermal conductivities for the same BN content and fall outside the systematic variation observed for the platelets, according to which one might have expected their thermal conductivities to lie between those for the $30 \mu \mathrm{m}$ and the $180 \mu \mathrm{m}$ platelets. It appears that, for the same $\mathrm{BN}$ content, the agglomerates give higher thermal conductivities than do platelets of the same size, indicating thus a clear effect of filler particle shape. This would be explained by the smaller surface area for agglomerates, and hence fewer interfaces for the phonons to cross. In contrast, the cure kinetics, for example as illustrated by the results in Fig. 3, correlate more closely with the specific surface area (SSA). We also note that, as anticipated in the previous section, the composites filled with $120 \mu \mathrm{m}$ spherical agglomerates do indeed have the highest thermal conductivity for a given $\mathrm{BN}$ content, thus giving rise to the minimum observed in Fig. 5.

The effect of filler particle shape on the thermal conductivity has not specifically been addressed by other authors; although particles of different shapes have been studied before, often the particle size is also different, making it difficult to identify the effect of particle shape while, as mentioned earlier, the SSA is often not quoted. For example, Zhu et al. [41] compare micro-BN platelets, with an average size of $7 \mu \mathrm{m}$, and nano-BN polygonal particles, with an average size of $70 \mathrm{~nm}$, and find that, for a given $\mathrm{BN}$ content, the micro-BN platelets have a higher thermal conductivity than do the nano-BN polygonal particles. This would appear to contradict our conclusion that agglomerates have the higher thermal conductivity, but this does not take into account the fact that the platelets are 100 times larger than the polygonal particles, and that larger particles have higher thermal conductivity. Likewise, Huang et al. [42] report that spherical BN particles, with a narrow size distribution of 200 to $400 \mathrm{~nm}$, have a lower thermal conductivity than do BN platelets ("flakes") with a diameter in the range 3 to $6 \mu \mathrm{m}$, but again the platelets are much larger than the spherical particles. On the other hand, Gaska et al. [18] compare platelet-like-shaped BN particles, with an average size of $13 \mu \mathrm{m}$, with spherical BN agglomerates of diameter $30 \mu \mathrm{m}$ 
and find that the larger agglomerates have a slightly higher thermal conductivity, which could be an effect either of size or of shape.

\section{Scanning electron microscopy}

From the discussion of the results presented above for both the cure kinetics and the thermal conductivity, it is evident that the interfacial surface between matrix and filler particles plays an important role. The quality of this interface can often be improved by, for example, the use of silane coupling agents. However, the surface treatment of $\mathrm{BN}$ particles is not easy, and a brief discussion of its effect, not always either positive or significant, on the thermal conductivity of epoxy-BN composites is given elsewhere [21, 22]. In the present work, we did not use any surface treatment of the particles or any coupling agent, and the matrix-filler interface has been investigated by scanning electron microscopy of the fracture surfaces of the cured composites, as illustrated in Fig. 7.

It can be seen that, for the platelets, there is generally a gap between the filler particles and the matrix, or between the individual platelets, resulting from poor bonding between filler and matrix. This gap represents a resistance to heat flow, interrupts the pathways for phonon transport, and hence leads to a reduction in the thermal conductivity of the composite. It should be borne in mind that these are fracture surfaces illustrated in Fig. 7, and that the fracture will follow the path of least resistance, where there is poor adhesion between filler and matrix. Nevertheless, we have shown earlier that this interface between matrix and filler is better in these epoxy systems cross-linked with thiol than when the cross-linking agent is a diamine [30], as a consequence of a Lewis acid-base interaction between the thiol and the BN. This interaction is reflected in the cure kinetics, whereby the peak exotherm during cure of the epoxy-thiol systems depends significantly on the BN filler content, as seen in Figs. 3 and 5, whereas no such effect is observed for the corresponding cure of epoxy-diamine systems.

In contrast, for the composite filled with the $120 \mu \mathrm{m}$ agglomerates, shown at the bottom right of Fig. 7, there is much greater continuity between particles and matrix, and between individual particles. The agglomerates are touching, and the particle-particle contact zone is embedded in a continuous coating of the epoxy matrix, which together create a continuous pathway for phonon transport. This results in a greater thermal conductivity for the agglomerates in comparison with the platelets.

The microstructure is, nevertheless, not ideal, as in this same figure it can be seen that there are significant voids between the agglomerates. These voids have the effect of reducing the thermal conductivity, and their existence is confirmed by the measurements of the density of the composites. For example, for the ETLBN $x$ - 60 system, the density of a composite fabricated with $47.4 \%$ by mass of $\mathrm{BN}$ in the form of $120 \mu \mathrm{m}$ agglomerates is $1.30 \mathrm{~g} \mathrm{~mL}^{-1}$ whereas that for a composite fabricated with the same mass\% of either 2 , 30 or $180 \mu \mathrm{m}$ platelets is $1.55 \mathrm{~g} \mathrm{~mL}^{-1}$. In order to achieve even higher thermal conductivities in epoxy-BN composites fabricated with agglomerates, it is necessary to eliminate, or at least reduce, this void content. One way to do this is by the
Fig. 7 SEM micrographs of fracture surfaces of epoxythiol-BN composites. Top left: ETLBN2-60, $\times 5000$, scale bar $5 \mu \mathrm{m}$. Top right: ETLBN30-60, $\times 1500$, scale bar $10 \mu \mathrm{m}$. Bottom left: ETLBN180-60, $\times 1500$, scale bar $10 \mu \mathrm{m}$. Bottom right: ETLBN120-60, $\times 500$, scale bar $50 \mu \mathrm{m}$
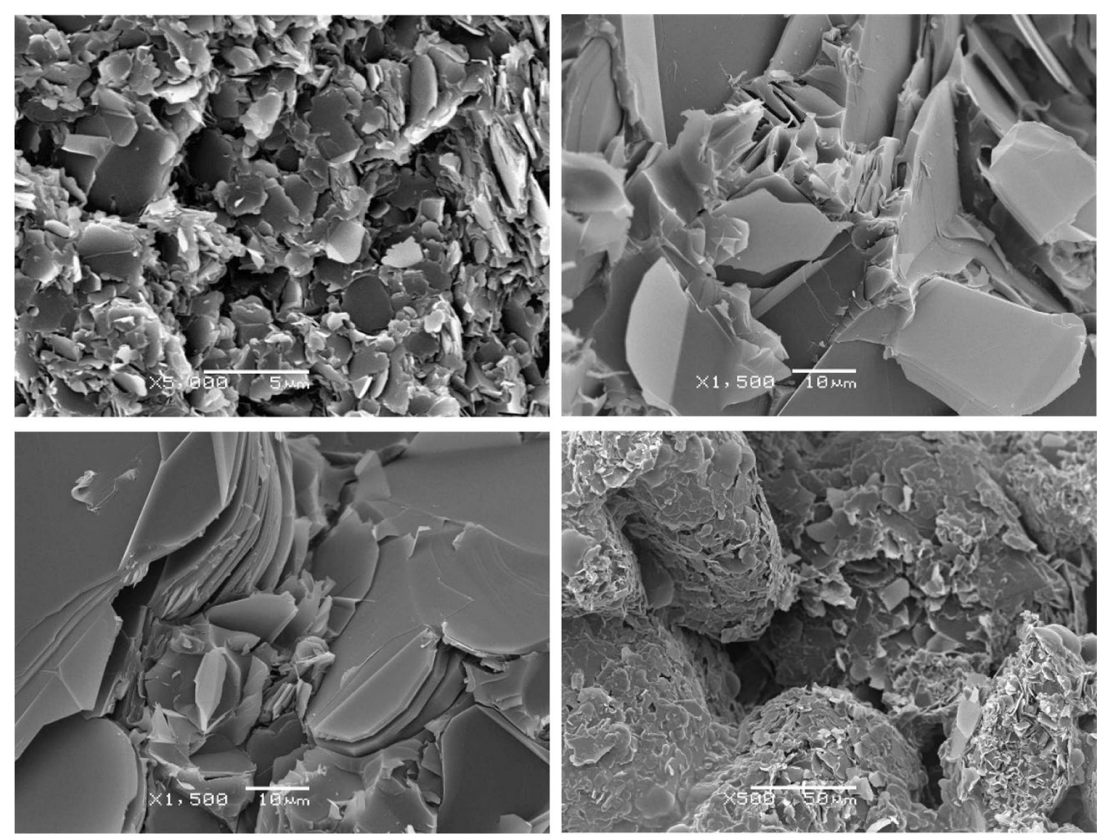
use of pressure during cure, and this approach is currently being investigated.

\section{Conclusions}

Epoxy-thiol composites filled with boron nitride $(\mathrm{BN})$ are excellent materials for the combination of electrical insulation and efficient heat transfer. The curing reaction of the epoxy composite systems has been studied by differential scanning calorimetry (DSC), and it is found that, for all of the composites prepared, the heat of reaction and the glass transition temperature of the fully cured materials are essentially constant. It is concluded that the BN filler particles do not influence the final network structure of the epoxy matrix. In contrast, the kinetics of the cure does depend on the $\mathrm{BN}$ content, the cure becoming increasingly retarded as the BN content increases. For non-isothermal cure in particular, the degree of retardation increases as the specific surface area (SSA) of the particles increases. The most dramatic effect occurs for the $2 \mu \mathrm{m}$ platelets, for which a kinetic analysis shows that the activation energy decreases on the addition of $\mathrm{BN}$ particles. For the cure kinetics to be retarded in this system on the addition of BN particles, therefore, it is concluded that the pre-exponential factor must decrease dramatically, which is attributed to a large increase in the absolute value of the entropy change of the reaction. This is associated with the immobilization of a significant proportion of the epoxy resin matrix in contact with the large interfacial surface area of these platelets. It is noted also that there is a certain acceleration effect in the cure reaction at low BN contents, most noticeable in the composites filled with $120 \mu \mathrm{m}$ agglomerates, which is attributed to heat transfer effects.

The thermal conductivity increases with $\mathrm{BN}$ content for all particle sizes and types. For a given BN content, the larger is the platelet the higher is the thermal conductivity, with the largest value of almost $4.5 \mathrm{~W} \mathrm{~m}^{-1} \mathrm{~K}^{-1}$ being achieved for composites with approximately 45 mass\% of the $180 \mu \mathrm{m}$ platelets. This dependence on BN platelet size mirrors the DSC results in that the greatest retardation of the cure kinetics correlates with the lowest values of thermal conductivity. The composites filled with $120 \mu \mathrm{m}$ agglomerates, though, follow a different pattern, and have the highest thermal conductivities, even higher than for the larger 180 $\mu \mathrm{m}$ platelets, indicating that the size and shape of the $\mathrm{BN}$ particles have separate effects on the thermal conductivity. The reason why composites filled with agglomerates give higher thermal conductivity is primarily associated with the reduced interfacial area in comparison with that for composites filled with platelets of the same size. In addition, from scanning electron microscopy of the fracture surfaces, it can be seen that there is a poor interface between the BN platelets and the epoxy matrix, which reduces the thermal conductivity, whereas for the agglomerates there is greater continuity between matrix and filler, and between the particles themselves. For both platelets and agglomerates, for the same BN content, the interfacial area increases as the particle size decreases, and hence higher thermal conductivities are obtained the larger is each type of particle.

Acknowledgements This work was financially supported by the Spanish Ministerio de Economia y Competitividad, Grant Number MAT2017-82849-C2-2-R.

\section{References}

1. Waldrop MM. The chips are down for Moore's law. Nature. 2016;530:144-7. https://doi.org/10.1038/530144a.

2. Moore AL, Shi L. Emerging challenges and materials for thermal management of electronics. Mater Today. 2014;17:163-74. https ://doi.org/10.1016/j.mattod.2014.04.003163.

3. Xu X, Chen J, Zhou J, Li B. Thermal conductivity of polymers and their nanocomposites. Adv Mater. 2018;30:1705544. https:// doi.org/10.1002/adma.201705544.

4. Singh V, Bougher TL, Weathers A, Cai Y, Bi KD, Pettes MT, McMenamin SA, Lv W, Resler DP, Gattuso TR, Altman DH, Sandhage KH, Shi L, Henry A, Cola BA. High thermal conductivity of chain-oriented amorphous polythiophene. Nat Nanotechnol. 2014;9:384-90. https://doi.org/10.1038/NNANO.2014.44.

5. Kim GH, Lee D, Shanker A, Shao L, Kwon MS, Gidley D, Kim J, Pipe KP. High thermal conductivity in amorphous polymer blends by engineered interchain interactions. Nat Mater. 2014;14:295300. https://doi.org/10.1038/NMAT4141.

6. Shanker A, Li C, Kim GH, Gidley D, Pipe KP, Kim J. High thermal conductivity in electrostatically engineered amorphous polymers. Sci Adv. 2017;3(7):e1700342. https://doi.org/10.1126/sciad v. 1700342.

7. Xu Y, Wang X, Zhou J, Song B, Jiang Z, Lee EMY, Huberman S, Gleason KK, Chen G. Molecular engineered conjugated polymer with high thermal conductivity. Sci Adv. 2018;4(3):eaar3031. https://doi.org/10.1126/sciadv.aar3031.

8. Seshadri I, Esquenazi GL, Borca-Tasciuc T, Keblinski P, Ramanath G. Multifold increases in thermal conductivity of polymer nanocomposites through microwave welding of metal nanowire fillers. Adv Mater Interfaces. 2015;2:1500186. https://doi. org/10.1002/admi.201500186.

9. Barako MT, Isaacson SG, Lian F, Pop E, Dauskardt RH, Goodson KE, Tice J. Dense vertically aligned copper nanowire composites as high performance thermal interface materials. ACS Appl Mater Interfaces. 2017;9:42067-74. https://doi. org/10.1021/acsami.7b12313.

10. Shen Z, Feng J. Highly thermally conductive composite films based on nanofibrillated cellulose in situ coated with a small amount of silver nanoparticles. ACS Appl Mater Interfaces. 2018;10:24193-200. https://doi.org/10.1021/acsami.8b07249.

11. Song H, Liu J, Liu B, Wu J, Cheng H-M, Kang F. Two-dimensional materials for thermal management applications. Joule. 2018;2:442-63. https://doi.org/10.1016/j.joule.2018.01.006.

12. Rybak A, Gaska K, Kapusta C, Toche F, Salles V. Epoxy composites with ceramic core-shell fillers for thermal management in electrical devices. Polym Adv Technol. 2017;28:1676-82. https://doi.org/10.1002/pat.4038. 
13. Hou H, Dai W, Yan Q, Lv L, Alam FE, Yang M, Yao Y, Zeng $\mathrm{X}, \mathrm{Xu}$ J-B, Yu J, Jiang N, Lin C-T. Graphene size-dependent modulation of graphene frameworks contributing to the superior thermal conductivity of epoxy composites. J Mater Chem A. 2018;6:12091-7. https://doi.org/10.1039/c8ta03937b.

14. Hong J-P, Yoon S-W, Hwang T, Oh J-S, Hong S-C, Leeb Y, Nam J-D. High thermal conductivity epoxy composites with bimodal distribution of aluminum nitride and boron nitride fillers. Thermochim Acta. 2012;537:70-5. https://doi.org/10.1016/j. tca.2012.03.002.

15. Rybak A, Jarosinski L, Gaska K, Kapusta C. Graphene nanoplatelet-silica hybrid epoxy composites as electrical insulation with enhanced thermal conductivity. Polym Compos. 2018;39:E1682-91. https://doi.org/10.1002/pc.24666.

16. Wattanakul K, Manuspiya H, Yanumet N. Effective surface treatments for enhancing the thermal conductivity of BN-filled epoxy composite. J Appl Polym Sci. 2011;119:3234-43. https ://doi.org/10.1002/app.

17. Kim K, Kim M, Hwang Y, Kim J. Chemically modified boron nitride-epoxy terminated dimethylsiloxane composite for improving the thermal conductivity. Ceram Int. 2014;40:204756. https://doi.org/10.1016/j.ceramint.2013.07.117.

18. Gaska K, Rybak A, Kapusta C, Sekula R, Siwek A. Enhanced thermal conductivity of epoxy-matrix composites with hybrid fillers. Polym Adv Technol. 2015;26:26-31. https://doi. org/10.1002/pat.3414.

19. Chung S-L, Lin J-S. Thermal conductivity of epoxy resin composites filled with combustion synthesized h-BN particles. Molecules. 2016;21:670. https://doi.org/10.3390/molecules210506 70.

20. Hu J, Huang Y, Zeng X, Li Q, Ren L, Sun R, Xu J-B, Wong C-P. Polymer composite with enhanced thermal conductivity and mechanical strength through orientation manipulating of BN. Compos Sci Technol. 2018;160:127-37. https://doi.org/10.1016/j. compscitech.2018.01.045.

21. Hutchinson JM, Román F, Folch A. Epoxy-thiol systems filled with boron nitride for high thermal conductivity applications. Polymers. 2018;10:340. https://doi.org/10.3390/polym10030340.

22. Daneshmehr S, Román F, Hutchinson JM. The surface modification of boron nitride particles. J Thermal Anal Calorim. 2019. https://doi.org/10.1007/s10973-019-09160-1.

23. Rivers G, Rogalsky A, Lee-Sullivan P, Zhao BX. Thermal analysis of epoxy-based nanocomposites: have solvent effects been overlooked? J Thermal Anal Calorim. 2015;119:797-805. https://doi. org/10.1007/s10973-013-3613-2.

24. CarboTherm Thermal Management Fillers; Product Data Sheet. Saint-Gobain Ceramic Materials. https://www.bn.saint-gobai n.com/sites/imdf.bn.com/files/carbotherm-bn-thermal-fille rs-ds_0.pdf. Accessed 29 Jan 2020.

25. Firdaus SM, Mariatti M. Nano-sized boron nitride epoxy composites for underfill application: effect of diluent and filler loading. J Mater Sci Mater Electron. 2015;26:774-83. https://doi. org/10.1007/s10854-014-2463-4.

26. Lim HS, Oh JW, Kim SY, Yoo M-J, Park S-D, Lee WS. Anisotropically alignable magnetic boron nitride platelets decorated with iron oxide nanoparticles. Chem Mater. 2013;25:3315-9. https:// doi.org/10.1021/cm401488a.

27. Wattanakul K, Manuspiya H, Nanumet $\mathrm{N}$. The adsorption of cationic surfactants on BN surface: its effects on the thermal conductivity and mechanical properties of BN-epoxy composite. Coll Surf A Physicochem Eng Aspects. 2010;369:203-10. https://doi. org/10.1016/j.colsurfa.2010.08.021.

28. Xu YS, Chung DDL. Increasing the thermal conductivity of boron nitride and aluminum nitride particle epoxy-matrix composites by particle surface treatments. Compos Interfaces. 2000;7:243-56. https://doi.org/10.1163/156855400750244969.
29. Hutchinson JM, Román F, Cortés P, Calventus Y. Epoxy composites filled with boron nitride and aluminium nitride for improved thermal conductivity. Polimery. 2017;62:560-6. https://doi. org/10.14314/polimery.2017.560.

30. Moradi S, Calventus Y, Román F, Hutchinson JM. Achieving high thermal conductivity in epoxy composites: effect of boron nitride particle size and matrix-filler interface. Polymers. 2019;11:1156. https://doi.org/10.3390/polym11071156.

31. THERMAL CLAD Insulated Metal Substrates. https://www.henke 1-adhesives.com/es/en/products/thermal-management-materials/ thermal-clad-insulated-metal-substrates.html. Accessed 29 Jan 2020.

32. Hammerschmidt U, Meier V. New transient hot-bridge sensor to measure the thermal conductivity, thermal diffusivity, and volumetric specific heat. Int J Thermophys. 2006;27:840-65. https:// doi.org/10.1007/s10765-006-0061-2.

33. Isarn I, Ramis X, Ferrando F, Serra A. Thermoconductive thermosetting composites based on boron nitride fillers and thiol-epoxy matrices. Polymers. 2018;10:277. https://doi.org/10.3390/polym 10030277.

34. Montserrat S, Román F, Hutchinson JM, Campos L. Analysis of the cure of epoxy based layered silicate nanocomposites: reaction kinetics and nanostructure development. J Appl Polym Sci. 2008;108:923-38. https://doi.org/10.1002/app.27297.

35. Morancho JM, Ramis X, Fernandez-Francos X, Salla JM, Konuray $\mathrm{O}$, Serra A. Curing and thermomechanical properties of off-stoichiometric anhydride-epoxy thermosets. J Thermal Anal Calorim. 2019;138:2865-72. https://doi.org/10.1007/s10973-019-08681-z.

36. Kumar S, Samal SK, Mohanty S, Nayak SK. Curing kinetics of bio-based epoxy resin-toughened DGEBA epoxy resin blend: synthesis and characterization. J Thermal Anal Calorim. 2019;137:1567-78. https://doi.org/10.1007/s10973-019-08080-4.

37. Isarn I, Massagués L, Ramis X, Serra A, Ferrando F. New BNepoxy composites obtained by thermal latent cationic curing with enhanced thermal conductivity. Compos Part A. 2017;103:35-47. https://doi.org/10.1016/j.compositesa.2017.09.007.

38. Bi Q, Hao L, Zhang Q, Wang P, Xu P, Ding Y. Study on the effect of amino-functionalized alumina on the curing kinetics of epoxy composites. Thermochim Acta. 2019;678:178302. https://doi. org/10.1016/j.tca.2019.178302.

39. Barghamadi M. Kinetics and thermodynamics of isothermal curing reaction of epoxy-4,4'-diaminoazobenzene reinforced with nanosilica and nanoclay particles. Polym Compos. 2010;31:14428. https://doi.org/10.1002/pc.20930.

40. Wu X, Zhao Z, Sun Y, Li H, Wang Y, Zhang C, Gong X, Wang Y, Yang X, Liu Y. Boron nitride nanoparticles with high specific surface area: preparation by a calcination method and application in epoxy resin. J Inorg Organomet Polym. 2017;27:1142-7. https ://doi.org/10.1007/s10904-017-0540-x.

41. Zhu BL, Ma J, Wu J, Yung KC, Xie CS. Study on the properties of the epoxy-matrix composites filled with thermally conductive AlN and BN ceramic particles. J Appl Polym Sci. 2010;118:2754-64. https://doi.org/10.1002/app.32673.

42. Huang L, Zhu P, Li G, Zhou F, Lu D, Sun R, Wong C. Spherical and flake-like BN filled epoxy composites: morphological effect on the thermal conductivity, thermo-mechanical and dielectric properties. J Mater Sci Mater Electron. 2015;26:3564-72. https ://doi.org/10.1007/s10854-015-2870-1.

Publisher's Note Springer Nature remains neutral with regard to jurisdictional claims in published maps and institutional affiliations. 